\title{
EDITORIAL
}

\section{A ANÁLISE DE DISCURSO CRÍTICA (ADC)}

\author{
Izabel Magalhães
}

\section{Abstract}

An issue for debate among CDA proponents is whether advocating critical assumptions exempts analysts from reflecting about their own practice. The issue is raised in relation to the discussion over the term adopted in Portuguese in the 1980's by the University of Brasília Language and Ideology Research Group: 'análise de discurso crítica (ADC)'.

Uma questão para discussão entre os adeptos da ADC é até que ponto a defesa de pressupostos críticos exime analistas de reflexão sobre a própria prática. Aliás, esse é um ponto abordado na obra de Chouliaraki e Fairclough (1999) em relação às práticas teóricas, pois essas práticas são sociais e por isso podem naturalizar desigualdades e hegemonias. Convém lembrar que o ponto já havia sido comentado por Fairclough ${ }^{1}$ (1992, trad. 2001): é imperativo refletir sobre a própria prática de análise de discurso, para que ela não seja apropriada por discursos institucionais.

Nesse sentido, cabe ponderar o seguinte: por que o termo 'análise crítica do discurso (ACD)' e não 'análise de discurso crítica (ADC)'? No momento, há uma demanda institucional pelo primeiro termo. No entanto, é preciso não esquecer que a linguagem, e certamente os termos que adotamos em nossa prática teórica, é parte de processos sociohistóricos (Magalhães, I., 2005). Em 1986, quando introduzimos o segundo termo

\footnotetext{
${ }^{1}$ Fairclough (1992, trad. 2001) sugere a reflexão de analistas críticos sobre os resultados de suas pesquisas: "há um processo difundido de tecnologização do discurso, que usa a pesquisa sobre o discurso para redesenhar as práticas discursivas e treinar as pessoas para usar novas práticas discursivas. A tecnologização do discurso é uma fonte para a engenharia cultural e social, e muitos analistas de discurso encontrarão objeções para o fato de ser usada e, certamente, para algumas formas em que é usada.” (Fairclough, trad. 2001: 291)
} 
em língua portuguesa, onze anos antes da publicação do livro organizado por E. R. Pedro (1997) em Portugal, ouvimos críticas da comunidade lingüística nacional. Diziam alguns: "discussões sobre linguagem e poder não são aceitas na lingüística”.

Quase duas décadas depois, algumas coisas mudaram. Parece que há um espaço para o debate sobre linguagem, poder e ideologia. Esse é o avanço que deve ser explorado por analistas críticos. Quanto ao termo a ser adotado, análise crítica do discurso não é nem mais nem menos correto do que análise de discurso crítica (ADC), termo usado em Cadernos de Linguagem e Sociedade, desde o volume 1, que foi publicado em 1995.

Porém, se considerarmos o processo sociohistórico no qual os termos estão situados, cabe manter o termo introduzido anteriormente pelo Grupo de Pesquisa de Linguagem e Ideologia da Universidade de Brasília.

\section{REFERÊNCIAS BIBLIOGRÁFICAS}

Chouliaraki, L. \& Fairclough, N. Discourse in late moderning. Rethinking critical discourse analysis. Edimburgo: Edinburgh University Press, 1999. Fairclough, N. Discourse and social change. Cambridge: Polity Press, 1992. Trad. Discurso e mudança social. Brasília: Editora Universidade de Brasília, 2001.

Magalhães, I. Introdução. A análise de discurso crítica. D.E.L.T.A., São Paulo, 21: 1-9 (Especial), 2005.

Magalhães, I. Por uma abordagem crítica e explanatória do discurso. D.E.L.T.A, São Paulo, 2 (2): 181-205, 1986.

Pedro, E. R. (org.) Analise crítica do discurso. Lisboa: Editorial Caminho, 1997. 